\title{
Sobre corpos fronteiras e processos criativos
}

\section{Bruna Martins Reis}

\author{
Universidade Estadual de \\ Campinas \\ Campinas, SP, Brasil \\ bru_psi@yahoo.com.br \\ orcid.org/0000-0001-6285-8131
}

Resumo I Este artigo apresenta discussões levantadas em uma pesquisa de doutorado, que investigou uma intervenção artística no campo da Saúde Mental, a partir de uma prática de dança desenvolvida com pessoas com transtornos mentais, realizada semanalmente no Centro de Atenção Psicossocial Antônio da Costa Santos, na cidade de Campinas - SP, ao longo de um ano. O recorte deste texto traz considerações sobre processos criativos como processos de subjetivação, discutindo a indissociabilidade entre processos artísticos e processos pedagógicos, estabelecendo, também, aproximações entre arte e clínica. Apresenta, ainda, algumas narrativas de participantes, colhidas ao longo das oficinas de dança, e que compõe a construção desta pesquisa cartográfica através de um dos dispositivos de registro criados, nomeado como "Diários de Vivências", que se propõe a expressar as diferentes vozes e experiências implicadas nesta criação.

PALAVRAS-CHAVE:

Dança. Loucura. Processos criativos.
On body borders and hybrid creative processes Abstract I This article presents discussions
that were raised during a doctorate's program
research which investigated an artistic
intervention in the field of Mental Health,
through a dance practice developed with people
with mental disorders, performed weekly at the
Centro de Atenção Psicossocial Antônio da
Costa Santos (Center for Psychosocial Care
Antônio da Costa Santos), located in the city of
Campinas - SP, throughout one year. This text
introduces considerations regarding creative
processes such as the process of subjectivation
while discussing the inseparability between
artistic and pedagogical processes, thus,
establishing connections among art and clinical
practice. It also presents a few stories from
participants, which were gathered during dance
workshops. These narratives integrate the
construction of this cartographical research
through the "Diário de Vivências" (journal of
experiences), one of the documenting devices
developed during the research, which aims at
expressing the multiple voices and experiences
involved in this creation.

KEYWORDS: Dance. Madness.

Creative processes.

Acerca de los cuerpos límite y los procesos creativos híbridos

Resumen | Este artículo se presenta discusiones surgidas en una investigación doctoral que investigó una intervención artística en el campo de la Salud Mental, a partir de una práctica de danza desarrollada con personas con trastornos mentales, realizada semanalmente en el Centro de Atenção Psicosocial Antônio da Costa Santos, de la ciudad. de Campinas - SP, más de un año. El recorte de este texto trae consideraciones sobre los procesos creativos como procesos de subjetivación, discutiendo la inseparabilidad entre procesos artísticos y procesos pedagógicos, estableciendo, además, aproximaciones entre arte y clínica. También presenta algunas narrativas de los participantes, recogidas durante los talleres de danza, y que conforman la construcción de esta investigación cartográfica a través de uno de los dispositivos de grabación creados, denominado "Diários de Vivências", que propone expresar las diferentes voces y vivencias involucradas en esta creación.

PALABRAS CLAVE: Danza. Locura. Procesos creativos.

Enviado em: 07/08/2021

Aceito em: 08/12/2021

Publicado em: 09/12/2021 
Este texto trata de corpos e espaços não habituais do campo das artes da cena, trata de uma experiência marginal e, às vezes, invisibilizada enquanto prática artística. Sobretudo, trata de vidas subalternizadas e excluídas por não corroborarem as normativas de corpos produtivos, inseridos em uma sociedade desigual, cuja política dominante é pautada em uma lógica antropo-falo-ego-logocis-heterocêntrica (ROLNIK, 2014), na qual corpos negros, trans, loucos, deficientes, indígenas, travestis, homossexuais, entre outros, são corpos que vivenciam processos insistentes de desumanização, corpos que não importam, como nos dirá Judith Butler (2020).

Este artigo é feito de rastros e de materialidades de vidas dissidentes. É parte de uma pesquisa de doutorado, cuja tese se intitula Corpo Fronteira - dança e loucura em estados de criação $^{1}$, realizada entre os anos de 2014 a 2018, no Instituto de Artes da Unicamp. O trabalho propõe uma investigação de uma prática de dança desenvolvida entre arte e loucura, entre dança e clínica e entre processos criativos e processos pedagógicos. Para tanto, aborda uma prática corporal com pessoas com transtornos mentais, usuárias do Centro de Atenção Psicossocial Antônio da Costa Santos $^{2}$, da cidade de Campinas, além de alguns de seus desdobramentos em outros processos artísticos e de criação de si, em uma perspectiva de indissociabilidade entre pesquisar, resistir, expor, cuidar e criar.

Neste percurso-pesquisa, foi desenvolvida uma oficina de dança, realizada semanalmente neste serviço de saúde, ao longo de um ano, na qual se buscou investigar algumas premissas da Técnica Klauss Vianna de dança e educação somática como uma das disparadoras das ações propostas, tentando compreender as atualizações necessárias do trabalho com esta técnica naquele contexto. Sondouse, enfim, os territórios corporais e subjetivos visitados a partir dos movimentos experimentados nas práticas durante o processo. Ao mesmo tempo, o corpo que escreve/pesquisa se lançou à experimentação das muitas materialidades vividas, e marcadas, como provocadoras de pesquisas de movimento em processos criativos concomitantes que, no decorrer dos quatro anos deste trajeto de pesquisa, escancaram a inseparabilidade das intensidades do corpo que dança como propositora de uma oficina no CAPS e do corpo que dança e performa em contextos cênicos ${ }^{3}$.

Neste sentido, os argumentos deste trabalho se articulam como campo expandido das artes performativas por compreender que esta prática permite explorar um modo de fazer/pensar a prática da dança em um contexto social fora do circuito usual das artes performativas, permitindo reiterar processos criativos

1 Este artigo apresenta trechos da tese citada. A mesma encontra-se disponível em: http://repositorio.unicamp.br/handle/REPOSIP/334354. Esta tese teve o apoio da Coordenação de Aperfeiçoamento de Pessoal de Nível Superior - CAPES.

2 Os CAPS são serviços de saúde abertos e comunitários, que fazem parte da Rede de Saúde Mental do Sistema Único de Saúde (SUS), e são lugares de referência e tratamento a pessoas com transtornos mentais graves. A prática desta pesquisa foi realizada entre 2015 e 2016 e contou com a colaboração e participação ativa da equipe e das pessoas usuárias deste serviço. É importante ressaltar que essa é a segunda oficina deste tipo realizada pela pesquisadora nesse mesmo serviço de saúde, sendo que a dissertação de mestrado "Corpo Fronteira: Clínica, dança, loucura - uma experiência" aborda essa primeira prática, iniciada 2009. Dissertação disponível em: http://repositorio.unicamp.br/jspui/handle/REPOSIP/313070.

${ }_{3}$ Ao longo da tese citada são apresentados outros processos criativos vividos durante a pesquisa, como marcas que explicitam a escrita como uma rede de afetos de ordens e registros diversos, na qual o fazer artístico e o fazer pedagógico são indissociáveis. 
implicados na produção de si. Assim, a dança abordada nesta experiência é tomada como disparadora de processos de subjetivação, que podem culminar na criação de outros horizontes de existência e que por assumir seus modos inabituais como qualidades, transbordam lógicas normativas dos códigos aceitos e dos espaços consensuais da arte enquanto instituição.

Neste artigo, serão expostas algumas considerações deste trabalho, que levanta uma discussão acerca de um "fazer em dança" que é, também, um fazer subjetivo, o qual dispara outros modos relacionais, ampliando possibilidades de movimentos de presença e de vida.

No presente recorte, algumas das discussões suscitadas aparecem como resquícios da imersão no campo de pesquisa, concebido como intervenção, na qual as conclusões foram apreendidas como aberturas de mundos, ou como um movimento de partilha dos estados e processos disparados no plano de criação que esta prática abre. É, neste partilhar, que algumas narrativas das pessoas participantes da pesquisa foram trazidas no texto-tese e mantidas neste artigo, esboçando minimamente alguns dos idiomas da cartografia gerada, posto que o texto deste trabalho se deu como uma assemblage 4 de vozes, sensações, reflexões e certos indizíveis, que buscou, na performatividade da escrita, dar visibilidade, também, às expressividades singulares dos diversos corpos envolvidos, acompanhando-os em suas danças e desatinos.

\section{Dos desatinos do acompanhar}

Acompanhar: estar junto com; deslocar-se junto; ter junto a si; cercar-se, rodear-se. Quando falamos em loucura, de qual modalidade de acompanhamento falamos? Por quais estratégias acompanhamos? Quem são os/as/es acompanhados/as/es ${ }^{5}$ ? Certamente, corpos marcados por estigmas sociais, preconceitos, histórias de segregação e marginalidade. Muitas vezes, falamos de corpos miseráveis, nascidos em famílias com pouco (ou nenhum) acesso à escolarização, à cultura e a oportunidades igualitárias de circulação social. Falamos em negros/as/es, prostitutas, usuários/as/es de drogas, homossexuais, moradores/as de invasões, moradores/as/es de ruas, moradores/as/es de barracos, buracos, bueiros, nômades do campo e das cidades, sujeitos considerados errantes. Falamos, também, em mães e pais de família, jovens bem-nascidos/as/es, evangélicos/as/es, espiritistas, umbandistas, budistas, católicos/as e ateus/ateias/ateies. Bilíngues, professores/as/es, musicistas, policiais, bancários/as/es, artistas, marceneiros/as/es/, aposentados/as/es, confeiteiros/as/es, médicos/as/es, domésticas, estudantes universitários/as/es, travestis, pedreiros/as/es, escritores/as, cantores/as, entre outros/as/es. Falamos do mundo e de pessoas para as quais a condição de vida tornou-se aquilo que historicamente foi nomeado como loucura, esta instituição cultural comumente associada à desrazão, ao fracasso social, ao desajuste, à exclusão e as anormalidades. Entretanto, nem sempre os espaços destinados ao tratamento e ao

4 A tese citada é composta por textos em diversos formatos, que trazem também narrativas e elaborações dos/das participantes envolvidos/as.

5 Esta grafia foi utilizada para abranger a diversidade de gêneros, não restrita ao sistema binário masculino/feminino empregado pelas normas ortográficas presentes na língua portuguesa até o momento. Esta forma de escrita se manterá em todo o texto a partir daqui. 
cuidado à loucura são tão igualitariamente ocupados.

Os CAPS acolhem, na maioria dos casos, uma população SUS dependente, o que, na lógica de funcionamento do acesso à Saúde Pública brasileira, indica uma camada da população considerada de classe média baixa, baixíssima ou miserável. Sendo assim, as relações estabelecidas pelas Redes de Saúde Mental extrapolam o âmbito dos cuidados clínicos, psicológicos e psiquiátricos; recebendo concomitantemente uma enorme demanda relacionada a questões sociais. São comuns as histórias de violência por parte de familiares, da comunidade, do tráfico e da polícia; são comuns as crianças abandonadas, famílias inteiras e numerosas que fazem uso de auxílios do governo para ter sustento, famílias com mais de um/a/e usuário/a/e no CAPS; é comum a falta de alimentação e é comum, evidentemente, o alto índice de agravamento das condições psíquicas em função das vulnerabilidades sociais ${ }^{6}$.

Deste modo, os serviços de saúde e suas equipes encontram-se, grande parte do tempo, tentando inventar estratégias que deem conta de tamanha complexidade; o que acaba por tornar esse acompanhar um trabalho de militância política, social e comunitária. Mas há, também, outros engajamentos, lutas sutis internas para perseverar no trabalho sem deixar-se contaminar a ponto de adoecer da dor do outro, das moléstias das coisas que, por vezes, parecem ser empurradas aos cantos malditos da sociedade. Aí, no dia a dia dessas guerrilhas intrínsecas, se descobre no corpo as potências e as impotências desse estar junto, no trabalho concomitante de cuidar do outro e cuidar de si.

E é no corpo, afetado e afetável de cada um/a/e, que caminha ao lado daqueles/as que, por seus modos inabituais de proceder a existência, são colocados/as/es à margem da sociedade, que se impõe o embate ético de cada encontro, movendo-se entre diferentes exigências. Deleuze (2016, p. 32) pontua que "o esquizofrênico" é como o limite da nossa sociedade, mas limite sempre conjurado, reprimido, execrado". Estar ao lado de pessoas e situações-limite é amplificar deslocamentos entre alegrias e tristezas, desamparo e criação, força e vulnerabilidade.

Entre limites e fragilidades, circulamos no trato com a loucura. Nos limites do conhecido, do esperado, das dores, das expectativas e das imposições. Há uma fraqueza que quer ser incluída nos processos vitais, aceita como força de relação. Um jeito sempre outro de encarar perdas e ganhos. De encarar, mesmo, a loucura e a sanidade. Como se fosse necessário carregar, no fundo dos olhos e ouvidos, as palavras de Nietzsche (1983, p. 89): "Há sabedoria nisso, sabedoria de vida, em receitar-se saúde mesma somente em pequenas doses".

$\mathrm{E}$, neste exercício de estar aberto a outras possibilidades de saúde, há que se pensar, também, na descoberta potencial de outras corporeidades, outros olhos e mãos para tocar corpos insólitos carregados de histórias-limite, transbordando aquilo

\footnotetext{
6 Estes dados puderam ser vivenciados no cotidiano de trabalho no CAPS, posto que integrei como psicóloga a equipe deste serviço ao longo de três anos (entre 2009 e 2012). Além disso, também atuei como profissional da equipe de outro CAPS da mesma cidade em anos anteriores, entre outras experiências no campo da Saúde Mental e Saúde Coletiva, vivenciadas desde o início de minha formação em psicologia.

${ }^{7}$ A esquizofrenia é um tipo de transtorno mental que faz parte do espectro das psicoses, é importante salientar, entretanto, que existem diferentes transtornos mentais que abarcam a vasta gama de condições psíquicas nomeadas como "loucura" e, embora a esquizofrenia seja bastante recorrente, o perfil dos usuários dos Serviços de Saúde Mental não se reduz a esquizofrênicos.
} 
que Ihes atravessa de distintas temporalidades e intensidades de existência. Neste ínterim, não se trata de conceber a loucura como perda ou como catástrofe originária no processo de socialização. É preciso, sempre, olhar para as singularidades destes corpos como territórios existências, processos de subjetivação, processos vivos íntegros como todos os seres viventes.

Neste sentido, provocar movimentos do corpo-loucura, trazer à tona uma discussão sobre estados corporais neste campo, requer o mesmo exercício ético de abertura ao encontro com a alteridade no/a/e outro/a/e e em si mesmo/a/e, posto que o corpo é feito de seus vividos, das alegrias e dos adoecimentos.

Anamaria Fernandes Viana $(2015)^{8}$ faz uma interessante consideração quanto à maneira de conduzir sua prática em um trabalho corporal desenvolvido em instituições especializadas no tratamento de pessoas autistas ou consideradas deficientes mentais - termo que a autora recusa, preferindo nomear tais pessoas como "pessoas extraordinárias". Segundo a autora, neste tipo de trabalho é necessário carregar o sentido da palavra experiência em duas vias distintas e complementares: como experimentação que contempla a tentativa e assunção de riscos; e como saber ou prática para a qual nos habilitamos. Desta forma, se considerarmos manter este aparente paradoxo, podem-se abrir possibilidades de caminhar, de forma mais conjunta, em uma certa honestidade cúmplice pelos caminhos desconhecidos destes encontros extraordinários.

$\mathrm{Na}$ forma como proponho, querer para você mesmo(a) uma forma de ignorância abre portas para a descoberta do que se produz no momento presente, viabilizando o aprendizado recíproco com aquele que carrega consigo a etiqueta do inferior, do incapaz, do impotente. E também permite, naturalmente a invenção. (VIANA, 2015, p. 14)

Sendo assim, uma cumplicidade dançante com estes corpos inabituais, "extraordinários", singulares e plurais, se dá como um tatear, no qual premissas técnicas precisam ser atualizadas para suportar a frequência das trocas intensivas. Com tais materialidades abre-se uma pequena trilha do que é esta cartografia desenhada a muitas mãos e que, mesmo ganhando forma em uma tese, segue sendo decifrada por se tratar de um trabalho que expõe, antes de tudo, percursos de criação e recriação da vida.

\section{Planos de criação e processos inacabados}

Quantos seres sou eu para buscar sempre do outro ser que me habita as realidades das contradições? Quantas alegrias e dores meu corpo se abrindo como uma gigantesca couve-flor ofereceu ao outro ser que está secreto dentro de meu eu? Dentro de minha barriga mora um pássaro, dentro do meu peito, um leão. Esse passeia pra lá e pra cá incessantemente. A ave grasna, esperneia e é sacrificada. O ovo continua a envolvê-la, como mortalha, mas já é o começo do outro pássaro que nasce imediatamente após a morte. Nem chega a haver intervalo. É o festim da vida e da morte entrelaçadas. (CLARK, 1997 apud ROLNIK, 2002, p 01)

8 O trabalho citado está registrado na Tese de Doutorado Dança e Autismo, espaços de encontro. Anamaria Fernandes Viana, Campinas - SP. Defendida na Faculdade de Educação da UNICAMP em 2015. 
De acordo com Cassiano Sydow Quilici, a transformação do cotidiano está atrelada à descoberta de um certo modo de agir que não é um mero esquecer-se nas ocupações ou nas cristalizações daquilo que são as ações diárias, voltadas à função econômica e prática do viver. Para o autor, a renovação do agir está relacionada, antes de tudo, à alteração significativa da própria percepção, saindo de modos codificados de ver o mundo para "uma abertura que sustenta o momento de espanto e admiração diante daquilo que surge, que passa e desaparece" (QUILICI, 2015a, p.143). Assim, criando condições de um olhar que acolhe a impermanência do que surge para daí apreender a "poética dos acontecimentos" (Ibidem, p. 143).

Deste ponto de vista, passaremos a pensar modos de articular este desengessamento do agir como processos latentes, presentes enquanto potência em toda e qualquer condição humana, mas que, para se efetivarem, exigem um nível de esforço e engajamento constante em um plano de (re)criação de si. Neste sentido, o corpo se reafirma enquanto lugar de embate de forças, no qual podem se dar pequenas revoluções no plano do sensível e do invisível que nos transforma constantemente, sendo estes micromovimentos fontes de constituição de nossas subjetividades no incessante trajeto de criar-se. Um movimento vital e autopoético de criar existência. Movimento que requer atenção, cuidado e deslocamentos; um certo estado de espreita do que se apresenta, limpando o olhar e a superfície sensível, para adentrar num plano de consistência dos encontros.

Ao levantar tais aspectos da renovação do agir, Quilici (2015), nos aponta a possibilidade de pensar na "arte da existência" como um trabalho contínuo de reposicionamento ético perante as ações cotidianas, levando-se em conta o caráter irrisório, ínfimo, daquilo que nos sucede, como potência para a desconstrução de aspectos automatizados encarnados em nossos corpos e em nossas relações.

A expressão "arte da existência" nos inspira aqui a falar de algo que se realiza nas mínimas ações, e que não se identifica necessariamente com aspectos consagrados e previsíveis para a realização de atividades artísticas, apesar de não excluí-los também. De qualquer forma, tudo começa com uma mudança de ponto de vista que desata o homem de um fazer e de um agir reativos, sobrecarregados de desejos de asseguramento do eu e de expansão do controle sobre as coisas. (QUILICI, 2015b, p. 143)

Podemos compreender, portanto, o trabalho sobre si como um fazer artístico imbricado em ações banais, comuns e cotidianas, fora do campo convencional das artes, mas que, através de dispositivos artísticos, pode ser potencializado. Tais dispositivos podem ser pensados em termos de um fazer (ou experienciar) de linguagens e práticas artísticas, como meio para acessar outros estados relacionais; bem como em termos contemplativos ou daquilo que é experienciado no encontroacontecimento com uma obra ou atividade artística.

É possível compreender tais deslocamentos, também, a partir da ideia de campo expandido da arte, considerando as formulações de Illeana Diéguez (2014) acerca da teatralidade social como campo de ação da arte, onde o limiar entre arte e vida se dissolvem, dando espaço a modos de conceber estados criativos de relação com o mundo.

Podemos, ainda, adentrar na poética de Lygia Clark, a partir das análises realizadas por Suely Rolnik, em suas proposições sobre criar condições para "atingir 
o singular estado de arte sem arte" (CLARK, 1966, p.30 apud ROLNIK, 1998, p. 05), condições estas diretamente relacionadas a um trabalho de restauração da subjetividade. Nesta fase da obra da artista, ela passa a utilizar seus Objetos Relacionais ${ }^{9}$, empregando-os diretamente na relação com seus sujeitos em sessões individuais, como dispositivos para desbravar outras possibilidades do ser, os forahumanos que transformam o dentro. Criam-se, assim, outras referências da existência objetiva e subjetiva, cunhadas como recursos para a "resgatar a vida como potência criadora, seja qual for o terreno onde se exerça tal potência" (ROLNIK, 1998, p. 05).

Deste modo, podemos pensar em diferentes estratégias, nas quais o pensamento que norteia um fazer artístico está mais diretamente implicado na criação de um campo de experiência no qual "o sujeito é lançado em diferenciação contínua pelo plano da experiência; o próprio sujeito é formado/diferenciado/transformado por esse plano. Plano de experiência como plano real de micropolíticas, sempre dinâmico e instável" (REIS; FERRACINI, 2016, p. 131). Assim, entrar num plano de experiência é abrir-se, permeável aos afetos, compondo com esse plano de forças, numa ética de ampliação de potência de ação. Ser lançado para fora, ao estrangeiro, seguindo por rumos impensados reconhecendo-se ou estranhando-se em outros espaços singulares. Como nos coloca Ana Maria Rodriguez Costas, sobre outra obra de Lygia Clark:

A palavra experiência tem o ex de exterior, de estrangeiro, de exílio, de estranho e também o ex de existência. A experiência é a passagem da existência, a passagem de um ser que não tem essência ou razão ou fundamento, mas que simplesmente "ex-iste" de uma forma sempre singular, finita, imanente, contingente (p. 25). A dinâmica da experiência, como na construção de uma fita de Moebius na obra "Caminhando" de Lygia Clark, implica em um movimento dentro-fora. O contato com o mundo exterior (a viagem, a travessia, o estranhar-se) reforça e é ao mesmo tempo possível, porque existe alguém, um singular, com contorno: um dentro, portanto. Mas, estranhar ou estranhar-se (resgatando o meu interesse em questões relativas às quebras de rotina da percepção) significa que houve um movimento rumo ao diverso, ao diferente, àquilo que não conhecemos, de nós mesmos e do mundo. (COSTAS, 2011a, p.5)

Desta vontade, algumas questões se colocam: como mirar o despontar da criação de territórios existenciais nos interstícios de um trabalho corporal, desenvolvido com pessoas com transtornos mentais? Por quais registros isso procede:

"Pra mim, foi um pouco difícil. Não sei se é porque tá frio ou se é porque eu tô precisando assim de caminhar mais, de ficar mais exercisada e quando fazer o exercício não ficar tão cansada. Daí sentir o estado da gente mais calmo, mais manso pra fazer os movimentos e as expressões, porque aquele

9 Termo cunhado por Lygia Clark para nomear os objetos criados por ela para o trabalho na obra "Estruturação do Self", na qual a artista passa a receber seus clientes em uma espécie de consultório experimental, em sua casa no Rio de Janeiro, para sessões nas quais utiliza tais objetos em relação direta com o corpo desses sujeitos. Sobre isso ver Rolnik, 2002; e o mini documentário Lygia Clark Memória do Corpo (1984), disponível em : www.youtube.com/watch?v=9ymjW6yVKAg 
controle que a gente faz deixa a gente mais ativa, o braço assim a gente vê que tá mais flexível. Não fica aquele peso no corpo de quem não faz nada, eu gostei sim. Pra mim também foi um pouco difícil porque eu tenho um certo problema nos braços e nas pernas, que eu tenho que ficar sempre sabendo é não olhar muito pra trás, eu olho mesmo pra ver. Se eu fico de um lado ou de outro, esquerda ou direita, então eu fico sempre lidando com o corpo, equilibrando. Também depois que dá o... depois que dá a hora de fazer, eu percebo que todo aquele exercício que foi difícil é uma mágica do corpo e depois que faz eu me senti bem. (Ana, transcrição de áudio, 28/04/2016) $)^{10}$."

Sem sucumbir ao risco de generalizações, as tramas de sentidos aqui tecidas são feitas por registros singulares, infames, pequenos; rastreando no lastro dos encontros vividos alguns ensejos, que parecem indicar a abertura de outros espaços, no corpo, nas relações, no seguir vivendo. Na descoberta de novos limites corporais, outras articulações e flexibilidades, desvelam-se também outros ânimos, outras forças. Eventos esses que não necessitam de comprovação externa para serem legitimados, mas que alteram sutilmente a "mágica do corpo", nas palavras de Ana, agindo naquilo que é a urgência de cada um/a/e. Seja um "acalmar", um "equilibrar", um olhar novo ou um "exercizar", cada um destes efeitos dizem sobre outros modos de se perceber, de se habitar e, sobretudo, de se ocupar de si mesmo/a/e. Seja por prazer, por provocação, por curiosidade, para criar danças ou para criar-se, numa artesania das coisas mínimas e indissociáveis. Seguindo na esteira das coisas que nos tocam e nem sempre são decifráveis ou analisáveis, posto que se situam num plano das sensações e nos deslocam a lugares ainda sem nome, zonas de estranhamento; o perceber de um pulso que desvela a criação de algo.

Rolnik (2002, p. 04) nos coloca que a "Sensação" é precisamente isso que se engendra em nossa relação com o mundo para além da percepção e do sentimento. Quando uma sensação se produz ela não é situável no mapa de sentidos de que dispomos e, por isso, nos estranha". Para lidar com este estranhamento, é necessário decifrar sensações desconhecidas, criando signos, que também serão decifrados, porém, sem explicações ou interpretações, inventando sentidos que os tornem visíveis e deem lugar, integrando-os ao mapa da existência a partir da mutação do sensível que, ao produzir sentidos, cria mundos. É nessa decifração geradora de universos que se funda o trabalho do/a/e artista e daí advém uma concepção de arte como "prática de experimentação que participa da transformação do mundo" (Ibidem, p. 4).

Ainda conforme a autora, por este prisma, podemos ampliar a noção do fazer artístico como prática estética. Esta implicada numa relação que ultrapassa o conceito de "obra" ou de resultado estético, sendo a própria prática considerada uma dimensão da obra que altera o mapa da realidade vigente, reafirmando a vida como potência de criação.

${ }^{10}$ As narrativas neste formato são de usuários/as do CAPS participantes da prática de dança, investigada durante o processo de pesquisa citado, as mesmas compõem a tese de doutorado mencionada. Os nomes dos/as usuários/as foram substituídos mantendo em sigilo suas identidades. As transcrições foram realizadas pela própria pesquisadora, a captação de áudio foi feita durante as rodas de conversa que ocorreram no momento final de cada dia da oficina de dança, compondo essa prática como mais um de seus movimentos. Tais transcrições são parte do "Diário de Vivências". 


\section{Povoamentos do sensível}

Se, no rastreio de certos deslocamentos, nos deparamos com seguimentos que podem ser confundidos ou comparados com os domínios da clínica e das terapêuticas, tais possibilidades devem ser pensadas como efeitos e não como proposições com esta finalidade. A aproximação com a clínica se dá pela possibilidade de interferência subjetiva, que é condição básica tanto deste espaço quanto dos processos artísticos, como trabalhos que atuam diretamente num registro ético, estético e político como potência de criação de mundos. É sob essa perspectiva que a possibilidade de efeitos, os quais podem ser, também, considerados terapêuticos, não é descartada, sobretudo quando os mesmos são referidos singularmente, pelo/a/e próprio/a/e participante da prática. Entretanto, é importante salientar, mais uma vez, que não houve um investimento específico nesta pesquisa em criar estratégias para este fim. O terapêutico, quando vislumbrado neste contexto, será considerado consequência de ações e propostas que visaram provocar o corpo a outras explorações sensíveis, expressas em danças, pausas, gestos, palavras, olhares. É pelos caminhos do corpo que algumas necroses afetivas e singulares são tocadas, sem objetivos terapêuticos pré-definidos.

Assume-se também, na esteira do que nos diz Viana (2015), a aposta de que práticas que não direcionam aos sujeitos considerados "anormais" propostas exclusivamente nas terapêuticas, constituem uma intervenção social emancipadora, que pode reverter olhares discriminatórios e mesmo valorativos quanto ao lugar do fazer artístico e o lugar da anormalidade em nossa sociedade.

Se tratados se transformam em regras e descobertas em técnicas, se "nossos corpos são socialmente constituídos e historicamente produzidos" (MARQUES, 2010, p. 08), e se a sociedade pode se revelar, tantas vezes, como uma prisão assustadora e sorrateira, devemos nos questionar sobre a importância da promoção de espaços de conscientização, de emancipação e de transformação - sobretudo no que diz respeito ao trabalho junto a pessoas socialmente discriminadas que levam em seus corpos marcas deixadas pela etiqueta da inferioridade (VIANA, 2015c, p. 37)

Interessa-me, portanto, ressaltar a dança como potência de todo e qualquer corpo. Estratégia de resistência. Não como oposição ou contraposição, mas por tornar possível um reinventar-se como possibilidade de vida e de arte. Engajando mais uma vez, o pensamento do fazer artístico como estratégia de ampliação de um campo de possíveis, força de coexistência, como nos diz Paulo Oneto:

Para além de sua maior ou menor técnica, o artista é um militante que vai quase na contramão da política institucional. Ele engaja ou milita por novos tipos de relação (ainda não pensados, e, portanto, "impossíveis") com uma realidade maleável. Em suma, o artista luta menos para realizar uma mudança na sociedade do que para possibilitar que enxerguemos essa sociedade de outro modo, como podemos depreender do pensamento de Gilles Deleuze, a questão da criação em sentido forte não é nunca realizar um possível, mas tornar possível. (ONETO, in LINS, 2007 p. 199) 
Ainda sobre esta aproximação quase indiscernível entre as propostas artísticas e um viés clínico-político de ação no mundo, voltamos às contribuições da obra de Lygia Clark para abarcar outra perspectiva de borramento de limites entre esses campos. Tomando como referência novamente o momento da trajetória da artista denominado "Estruturação do Self", no qual a mesma passa a considerar "o corpo e o envolvimento do outro como condição de realização da obra" (ROLNIK, 2002, p. 07), retomamos a ideia da necessidade de mobilizar outros sentidos no acontecimento-obra, recolocando-a como a própria relação que se estabelece entre artista e "público", no caso desta obra nomeados como "clientes" (Ibidem, p.7). Considerando aquilo que se passa entre os corpos como criação de condições para que algo aconteça, desconstrói-se aspectos formais da obra enquanto objeto, passando a considerar a ação sobre o corpo subjetivo como lugar onde a criação se opera.

No trabalho desta artista, tais ações consistiam em diversas estratégias de mobilização do corpo, mediadas pelos "objetos relacionais", já citados anteriormente, com o intuito de entrar em uma zona sensível de deslocamento do plano subjetivo. Assim, "Favorecendo a exposição da subjetividade ao além do humano no homem: o autêntico bicho (o vivo)" (ROLNIK,1993a, p. 04), reconquistando condições para que a subjetividade suporte a contingência das formas, superando um "dentro absolutizado vivido como identidade" (Ibidem, p. 5), desmascarando na existência individual e coletiva o escoamento dos processos de subjetivação.

Conforme Rolnik, o trabalho de Clark reitera à arte a capacidade de acolher o rompante do bicho, do não humano, como apelo à criação. Dando visibilidade à emergência de fluxos criadores de forças de vida que, num contexto onde as subjetividades se encontram reduzidas à esfera mercadológica, são tomados como desestabilizadores fora dos contornos artísticos, pela escassez de recursos sensíveis e a cronificação da ideia de subjetividade como individualidade fixa.

Quando a experiência desta escassez se apresenta como limite desestabilizador, entramos no domínio do trabalho clínico que, por sua vez, irá operar através de outros recursos com os mesmos parâmetros de restauração subjetiva que a arte como compreendida aqui.

Fora da arte e do artista, cada grasnar do bicho, cada morte de uma figura do humano, tende a ser vivido como ameaça de aniquilamento total. Essa sensação é tão aterrorizadora que pode levar a reações patológicas. Quando isso acontece caímos no domínio totalmente outro: o da clínica. (ROLNIKb,1993, p.03)

Deste modo, a concepção de arte levantada pela artista se funda como híbrido, atuando no enfrentamento do trágico a partir da ação direta sobre a subjetividade do vivo. $E$, neste híbrido, encontramos aquilo que é, também, por outras vias, o enfrentamento da clínica enquanto possibilidade de lidar com sintomas ou traumas, advindos da desestabilização completa do seu lugar como humano a partir da impossibilidade de gerir impulsos decorrentes dos contraditórios movimentos do estar vivo. Concepção esta que reafirma um laço entre os dois campos, lugares de embates éticos e políticos, em relações de reciprocidade de criação: 
Vimos que a clínica nasce exatamente em um contexto sócio-cultural que cala o grasnar do bicho, enjaulando-o na arte, de tal modo que no resto da vida social, ele tenda a ser vivido como trauma. É curioso lembrar que Lygia deu o nome de "estado de arte" para aquilo que em nós escuta esse grasnar e Deleuze, o nome de "estado de clínica", para aquilo que em nós o cala. O híbrido arte/clínica que se produz na obra de Lygia explicita a transversalidade existente entre essas duas práticas. Problematizar essa transversalidade pode mobilizar a potência crítica presente tanto na arte, quanto na clínica. Em primeiro lugar, esse híbrido torna visível uma dimensão clínica da arte: a revitalização do estado de arte, implica potencialmente uma superação do estado de clínica. E, reciprocamente, ganha visibilidade uma dimensão estética da clínica: a superação do estado de clínica, implica potencialmente uma revitalização do estado de arte. (ROLNIK,1993c, p. 06)

Ainda no sentido destas aproximações, olhando pelo prisma mais direto das práticas corporais, as reflexões de Hubert Godard acerca dos trabalhos de Lygia Clark trazem outra compreensão. O autor trata suas obras como dispositivos que exercem um trabalho artesanal de restauração subjetiva, lidando diretamente com padrões desencadeados por um certo empobrecimento de nossas capacidades perceptivas:

[...] frequentemente, a história da percepção vai fazer com que, pouco a pouco, eu não possa mais reinventar 05 objetos do mundo, minha projeção vá associá-los sempre da mesma maneira. Ou seja, vejo sempre a mesma coisa. Sempre através do filtro de minha história. Portanto, poderíamos dizer que há uma "neurose do olhar". Algo que diria respeito ao fato de que o meu olhar não é mais capaz de voltar a desempenhar uma subjetividade em sua relação com o mundo. (GODARD, 2006, p. 05)

Este autor situa as proposições de Lygia como um híbrido. Ele reconhece que todo trabalho que toca aspectos da percepção está, necessariamente, acessando aspectos psíquicos, posto que a constituição destes dois campos é indiscernível. Deste modo, quando nos propomos a suscitar, através da experiência perceptiva, a ampliação de espaços no corpo, estamos, necessariamente, ampliando possibilidades de movimentos subjetivos. Criando, portanto, condições para que outros modos de vivenciar o corpo transformem nossa história e nosso presente.

Também neste sentido, na esfera dos fazeres da dança, Godard (2004, p. 03) coloca: "não posso mudar o meu gesto se não mudar a relação que mantenho com o meu corpo e com o espaço através da percepção". Assim, ampliamos o olhar para a noção de um certo cultivo de outras lógicas de encontro com o corpo para ganhar outros poros, peles, ossos, olhares, escuta. Para que estes possam abrir o potencial para ação, dissolvendo a cisão subjetiva imposta por um cotidiano que reitera a estagnação dos processos subjetivos voltados à criação, por encontrar-se distanciado de forças de enfrentamento e das frequências dos pulsos vitais (ROLNIK, 2014).

Ao desmontar, mesmo que em pequenas proporções, o corpo anestesiado do cotidiano para dar passagem à experiência de outros fluxos de sensações, afetos, desejos e percepções, mantendo algum nível de "não forma", premissa do imprevisível dos encontros, investimos em uma "poética da construção do homem, 
a partir da abertura para outras possibilidades de ser" (QUILICI, 2015c, p 120). Ou seja, como a capacidade de uma arte que se afirma enquanto tal por assumir seu desafio ético e político de ação no mundo, pelo engajamento em processos de subjetivação.

Quando se inauguram outras qualidades para os encontros com aquilo que é chamado de loucura e aquilo que é chamado dança, criam-se, também, outras temporalidades e materialidades de vida, cunhadas em um escavar espaços de vazio, um desocupar o piloto automático do corpo em nome da retomada de outros fluxos. Contingências estas que atualizam presenças singulares, em relação.

No diálogo que se segue, José Pedro nos deixa ver algumas inquietações suscitadas a partir de um outro modo de perceber seu corpo, em uma espécie de saber das miudezas que abre espaço para outro habitar-se:

"José Pedro: Aí, você faz um trabalho também de percepção, da gente perceber certas partes do corpo. É como se você tivesse olhando assim uma parte do corpo, mas só que é sua consciência que faz essa seleção. Você vai falando e ouve e já detecta imediatamente a parte do corpo. Você falava "região lombar" eu ... pelo menos eu consigo ver essa parte do corpo e frisar aquela parte lombar que eu ouvi, então além disso é uma aula de anatomia também. É aplicar né.

Bruna: É interessante que cada um tem uma apreensão do trabalho. Essa percepção da anatomia é um pouco mais fina, às vezes demoramos pra chegar nela. Porque tem muita camada até a gente chegar no osso, muita camada de tensão, muita camada de pensamento... então a ideia é ir chegando nessa anatomia do corpo sentido.

José Pedro: Eu gosto que parece que desenvolve uma percepção assim que a gente não costuma ter no dia-dia, principalmente no movimento, nos movimentos que não são comuns assim, por exemplo, andar de lado, andar pra trás e sincronizar a forma de observar o ambiente a sua volta assim. Que vai mudando conforme você muda o foco; isso influencia o movimento que você tá fazendo, você vira de lado, de costas, de frente. Hoje, eu aprendi também o plano, o plano médio, plano baixo e isso daí aumenta mais ainda o leque de atividades de criação que você pode encontrar, essa rotina assim de andar sempre da mesma forma, com a mesma postura. Você acaba trabalhando também a parte do corpo que também não é comum às vezes de trabalhar.

Bruna: Interessante isso que você está falando sobre a atenção. Vocês podem tentar observar, agora na volta do CAPS para a casa, se dá pra levar essa atenção para esses outros espaços ou se a gente desenvolve aqui e fica aqui. Quer dizer, tentar observar isso no dia-dia, no cotidiano. Se essa outra atenção pode ser levada para o cotidiano". (Trechos de diálogo, transcrição de áudio, Diário de Vivências, 14/10/2016)

A aquisição de uma outra consciência está, também, atrelada a novas materialidades, como contornos ou pontes, que permitem outras possibilidades de trocas, que são, por sua vez, partes das marcas que alteram a cartografia maleável do presente. 
Consciência esta que não será pensada aqui como síntese, análise, interpretação, mas como um tatear que toca conteúdos presentes no corpo, incorporando-os aos seus repertórios de ação, como prolongamentos de movimentos internos e externos. Como descobertas de outros universos ativos, outras superfícies-peles-contornos que estabelecem trocas e relações. Como nos dirá Letícia Teixeira:

O trabalho corporal requer algumas condições ou meios básicos para fazer com que a consciência seja o elemento atuante. Primeiramente, não se racionaliza nem se interpreta. Trata-se de uma atividade corporal cuja principal modalidade é o sentido, independentemente do que esteja sendo expresso ou acontecendo: sentido de mal-estar, de prazer, sentido tátil, sentido de amplitude, de sonolência, de devaneio etc. Apesar de equivaler a um "senso interior", a consciência existe em relação com o meio, com o "objeto" e não com relação consigo mesma, ou seja, é preciso essa troca de estado de si perante o momento real do "aqui (tempo) e agora (espaço)" (TEIXEIRA, 1998, p.75-76).

Atuar nesta margem, seja no contexto da Saúde Mental, seja em contextos convencionais da dança ou das artes da cena, implica princípios de processos que aceitam o transitório para colocar-se em estado de (re)criar ação, concebendo cada gesto por vir como um espaço de vida que se inaugura. Assumindo que, a cada novo passo, um mundo se desloca, sem certezas, na impermanência daquilo que é o estar vivo/a/e. "É dessa familiaridade paradoxal com o informe e com a impermanência, vivida no próprio corpo e nas relações, que poderá surgir uma nova qualidade de ação e presença" (QUILICI, 2015d, p.122).

Se, nesta prática, outros povoamentos se iniciam por ações simples - como percepção da respiração, o toque no próprio corpo, a percepção do peso e das temperaturas, o reconhecimento das articulações e das tensões, a escuta das necessidades do corpo de cada dia - estas devem ser pensadas como entradas ou convites às entradas que permitam alcançar outras possibilidades de se relacionar consigo e com outros corpos.

A narrativa de Ana nos conta algumas gradações desses reposicionamentos:

"Eu percebi que minha perna estava adormecida pro uso, só uma, não tinha peso nem vida e quando a gente fez o peso pro chão eu descobri isso, e na caminhada eu percebi que tenho que ser perseverante pra por força no pé e ganhar impulso pra ir adiante" (Ana, Diário de Vivências $\left.{ }^{11}, 15 / 12 / 2016\right)$.

De acordo com Jussara Miller, o corpo em estado exploratório coloca vivências internas em relação constante com o entorno, ganhando consciência do movimento ao mesmo tempo em que assume as transformações de si mesmo, emergindo um plano de criação em sensações e reverberações variadas que são incorporadas "revelando que o corpo é vestido de seus vestígios" (MILLER, 2012, p. 118).

Nesta via, voltamos àquilo que Godard (1995) nomeia como esvaziamento do

11 O Diário de Vivências foi um dispositivo que também contou com a escrita livre, realizada no momento da roda de conversa após as práticas de dança, nele os participantes poderiam registrar suas sensações, percepções, memórias ou apenas algumas palavras suscitadas pela dança ali vivida. 
espaço da ação para deixar surgirem outras qualidades de relações perceptivas e ativas. Há que se esvaziar o sentido do gesto para atingir um estado de vazio que abre um novo potencial, como tatear um espaço de suspensão que desconstrói os registros conhecidos de como e com o quê criar.

Mas, se também é do corpo dito "louco" que falamos, de suas desconstruções de padrões, temos que olhar para outros tipos de esquemas construídos, posto que são corpos cotidianamente apaziguados por intervenções medicamentosas e que vivem às margens do acesso a diversos lugares de convívio, tendo, muitas vezes, suas vivências corporais empobrecidas, seja pelo uso contínuo de medicamentos por longos períodos e/ou pelo próprio estado psíquico. Corpos vistos, historicamente, como menos humanos, corpos silenciados e que vivem, na maioria das vezes, contextos de contenção socialmente produzidos, nos quais a naturalização de um certo padrão de uso de medicamentos e seus efeitos colaterais é comum, de modo que o entorpecimento diário, o excesso de sono, o excesso de apetite, a impotência sexual, os movimentos involuntários, entre tantos outros efeitos desagradáveis, passam a fazer parte do campo das loucuras, como sintomas secundários.

Tais questões tão delicadas não passam despercebidas no trato com tais sujeitos, sobretudo quando nos propomos a cuidar de seus corpos. Elas permeiam a investigação desta pesquisa e estabelecem critérios de prudência em que falar da desconstrução de padrões corporais e de movimentos exige um certo limite. Nele, está implícito o duplo trabalho de descontruir hábitos e criar outras bordas que deem condições de cada um/a/e cuidar-se a seu modo.

Prudência que se apresenta, também, quando assumimos outra relação de troca na qual se desvela no corpo de quem pesquisa e/ou dança junto, novos contornos para enfrentar os diferentes espaços de criação e de vida. Como nos diz Viana:

Partilhando o ato de dançar, refletindo sobre a dimensão ética e estética de sua prática, o artista abre todo um espaço de emergência, contaminandose, transformando-se. Ao democratizar seu espaço e se permitir aprender como essas pessoas tão discriminadas, desprezadas e rejeitadas, ele está refletindo sobre seus próprios limites, tanto quanto sobre seus conceitos de dança e de normalidade. (VIANA, 2015d, p. 15).

\section{Resistências, precariedades e outras paisagens}

Ainda nesta trilha, parece importante abordar certo aspecto de alguns processos artísticos que acessam estados de coisas que escapam a ordem do entendimento, adquirindo um caráter de catarse ou de uma espécie de cura. Isto que, por vezes, tem sido nomeado como terapêutico, mesmo não estando referendado pela prática de um/a/e terapeuta, mas, sim, pela prática de um/a/e artista, e que pode ser lido, nos termos da discussão levantada anteriormente, como dispositivo que opera ressignificações sensíveis e engendra outras possibilidades de partilha do comum.

Pode-se dizer que certas práticas, artísticas ou não, podem ser vistas como estratégias de produção de comum, de enlaces coletivos, de atualizações de forças que se fazem no entre, como lugares de potência para a "reinvenção das coordenadas de enunciação da vida", como nos diz Peter Pál Perbárt (2013, p. 129). 
Isto dá legitimidade à existência, sem o julgamento dos sistemas representativos, em uma política das coisas ínfimas que acolhem singularidades, atualizam urgências, reformulam espaços, requalificando o nós como conexão vital.

Trata-se, então, de conceber o comum como premissa que contempla a multiplicidade e a singularidade, sem unidade prévia, sem forma ideal, mas como um "reservatório de singularidades em variação continua, uma matéria a-orgânica, um corpo-sem-órgãos, um ilimitado (apeiron) apto às individuações mais diversas" (PELBART, 2003, p. 30). Deste modo, quando nos posicionamos em uma prática, em uma ação, ou em uma relação, com a perspectiva de estabelecer trocas sensíveis em conexões múltiplas e heterogêneas, falamos, também, em composições e recomposições que atualizam as condições de comum, já presentes como virtualidade em cada corpo singular.

E, por esta via, podemos, ainda, recolocar a questão da resistência como potência de criação que torna possível outros estados de composição, construindo novos critérios de assimilação das heterogeneidades que nos constituem em um plano comum, reificando a diferença e a multiplicidade como condição da vida. Sentido este que, mais uma vez, nos aproxima da ética clínica; aproximação que não busca fundir a ação da arte e da clínica, mas atualiza algumas vertentes que ampliam a função social de ambos os campos. Como nos sugere Elizabeth de Araújo Lima, a partir de uma perspectiva da prática clínica como processo que acolhe o inacabado, a precariedade, a anomalia enquanto potencialidades:

Nesse sentido, anomalia, precariedade e inacabamento encarnam forças de resistência à modelização dos funcionamentos e dos corpos e se aproximam instigadoramente da arte, seja do produto artístico, seja do processo de criação.

A clínica, nesta nova configuração, é aquela que se faz no território. Ela não está voltada para a remissão dos sintomas, mas para a promoção de processos de vida e de criação, e poderá, portanto, comportar uma outra saúde. Não uma saúde de ferro dominante, mas uma irresistível saúde frágil, como diria Deleuze (1997), marcada por um inacabamento essencial que, por isso mesmo, pode se abrir para o mundo; uma saúde tal, que não somente se tem, mas que constantemente se conquista ainda, e se tem de conquistar, porque se abre mão dela outra vez, e se tem de abrir mão! (LIMA, 2006, p. 327).

Quando falamos em uma clínica que se faz como resistência por acolher modos diversos de lidar com a precariedade dos processos vitais ou mesmo por engendrar novas configurações ao que seria uma "boa saúde", por quais vias os processos que se fazem híbridos, entre arte e saúde, se engajam na produção de outras concepções de saúde (ou de outras saúdes)?

Isabelle Ginot (2010) traz uma importante discussão no campo das práticas somáticas concebendo-as como "somato-políticas" e processos de "desassujeitamento" dos corpos. A autora aborda este tema, sobretudo, quando desenvolve tais práticas com públicos em situação de precariedade social e de saúde, com doenças socialmente marginalizadas, que incidem diretamente sobre a corporeidade e a vida social desses sujeitos. ${ }^{12}$ Neste sentido, a doença constitui um 
modo de construção discursiva e subjetiva, forjada a partir do saber médico, que historicamente tem o poder de interpretar, predizer e avaliar o corpo, suas ações e a própria capacidade de vida dos sujeitos, especialmente, quando se trata de doenças consideradas crônicas. De maneira que a experiência do adoecimento acaba por constituir uma espécie de "autoridade" sobre o gesto, inscrevendo marcas profundas na imagem corporal e nos modos de relação social, acometendo diretamente as atitudes corporais - mesmo quando o processo de adoecimento não está diretamente à ligado estrutura física, à postura ou à incapacidade de mobilidade.

Conforme a autora, é nesta via que a prática da educação somática pode atuar como um dispositivo para empoderar e criar outros horizontes para a experiência do adoecimento. Conferindo às práticas corporais não terapêuticas, como o caso da dança abordada aqui, possibilidades de um trabalho de escuta sensível, em que se constitui um processo de reconexão ao sentir em experiências estéticas as quais ampliam a relação entre arte e vida, saúde e doença.

Se, seguindo Foucault, é através do controle sobre os corpos que as sociedades exercem a "captura" sobre os sujeitos, as práticas somáticas como práticas de aprendizagem e de invenção de si - podem se constituir como ferramentas de resistência? (GINOT, 2014a, p. 17). (Tradução minha $)^{13}$.

Explorando tal questão, somos convidados/as/es a olhar para as doenças crônicas como um elemento, entre outros, que afeta a gestualidade e a organização postural, o que leva a questionamentos quanto ao "lugar do corpo" ou, sobretudo, a ausência do corpo e do gesto nos contextos do acompanhamento médico-social. Vale lembrar que as leituras corporais, nestes contextos, são realizadas, na maioria dos casos, como análise dos sintomas relacionados a um diagnóstico específico. Com isto, os estados corporais aparecem como resultado do controle social que é exercido sobre o sujeito e como causa de impedimentos, justificando a impossibilidade de cumprir objetivos fixados pela sociedade, sejam eles "produtivos", como a integração social e o trabalho, ou o cumprimento de regras sociais.

Descobrimos a que ponto as análises de Foucault sobre o biopoder se encarnam precisamente na gestão dos corpos dos usuários de instituições médico-sociais, que fabricam a fragmentação do vivido atribuído a diversos territórios: aquele da doença, controlado pela injunção de produtividade; aquele da identidade, controlado pelas categorizações sociais (imigrante, homem, mulher, homossexual...) e a injunção da "integração"... Sobretudo, descobrimos a fineza de análise e de interpretação da experiência corporal por aqueles ditos sem voz, e a potência de invenção e de apropriação dos potenciais do gesto oferecidos por nossa técnica, para apontar desejos e

- Association d'Individus en mouvements engagés, trabalhos e pesquisas práticas direcionadas a portadores de HIV(ditos soropositivos), frequentadores de serviços de atenção e apoio a este público; que no contexto da França, são também considerados pessoas em situação de fragilidade social e de saúde; sobretudo por se tratarem muitas vezes de imigrantes, homossexuais, pessoas marginalizadas de diversos modos. Tais pesquisas práticas são referendadas pelo método Feldenkrais de educação somática.

13 " $\mathrm{Si}$, en suivant Foucault, c'est par une emprise sur le corps que les sociétés font "prise" sur les sujets, les pratiques somatiques - comme pratiques d'apprentissages et d'invention de soi - pourraient-elles se constituer en outils de résistance?" 
intenções que não havíamos imaginado. (GINOT, 2014b, p. 2, tradução $\operatorname{minha})^{14}$.

Ainda conforme a autora, a prática somática, nestes contextos, pode ser pensada como prática impura ou mista, onde circulam gestos, toques, textos, palavras, através de espaços heterogêneos que partilham sentires e conceitos sem distinções hierárquicas, friccionando diálogos entre múltiplas especialidades, experimentando os contatos inesperados entre diferentes modalidades de saberes descontextualizadas.

É com esta perspectiva que se concebe um uso político das somáticas, forjado como um saber prático que inclui os saberes do corpo de usuários/as/es e, quando inseridos no seio de uma instituição de saúde, "abrem de forma radical um espaço tempo de exceção onde se fabrica um "comum", também frágil e provisório, seja ele de gestos, de afetos ou de palavras" (GINOT, 2014c, p. 25) ${ }^{15}$. Compreensão que não exclui um horizonte estético, mas atualiza seus sentidos.

Ginot assume uma proposta somática endereçada às pessoas ditas "sujeitos à precariedade", ou "sujeitos da precariedade", - assujeitados/as/es a ela e a um conjunto de dispositivos sociais encarregados de lhe contrapor -, como possibilidade de cuidar do imaginário do gesto, garantindo sua potência de re-subjetivação, presente em cada sujeito como contingente imprevisível de re-existência. Ou seja, "o não determinável é aqui precisamente isto que está fora de representação, fora de determinação identitária, mas no horizonte sempre reconstituído de suas relações de alteridade" (GINOT, 2014d, p. 25) (tradução minha) ${ }^{16}$.

Conforme Violeta Salvatierra ${ }^{17}$ (in GINOT, 2014, p. 118), parte significativa deste processo de re-subjetivação se dá a partir da elaboração coletiva, também no caso dos trabalhos desta autora, realizada a partir das conversas após cada prática corporal. Segundo a mesma, tais momentos permitem tecer palavras encarnadas que criam possibilidades de "articulações discursivas, sustentadas por potentes processualidades afetivas, que recompõem os saberes de si e elaboram novas organizações do sentir a potenciais desassujeitamentos"18. Tais conteúdos são considerados "enunciações de si", ancorados em dinâmicas de uma territorialidade inter e trans-subjetiva, que abrem devires capazes de servir de vetores a outros horizontes do desejo e das ações dos participantes. A autora nomeia os compostos

\footnotetext{
14 "Nous avons découvert à quel point les analyses de Foucault sur le biopouvoir s'incarnent précisément dans la "gestion" des corps des usager. ères.s par l'institution médico-sociale, qui fabrique la fragmentation du vécu assigné à divers territoires: celui de la maladie, contrôle par la logique médicale; celui de l'action (et de l'activité), contrôle par l'injonction de productivité; celui de l'identité, contrôle par les catégorisations sociales (migrant.e, home, femme, homossexuel.le) et l'injonction de "I'intégration "... surtout, nous avons découvert la finesse d'analyse et d'interprétation de l'expérience corporelle par ceux. celles que l'on dit sans voix, et la puissance d'invention et d'appropriation des "potentiels de gestes" offerts par nos techniques, pour server des désirs et intentions que nous n'avions pas imagines."

15 "(...) ouvrent de façon radicale un espace-temps d'exception où se fabrique un "commun", aussi fragile et provisoire soit-il, de gestes, affects et de paroles."

16 "Le non-déterminable est ici précisément ce qui se tient hors représentation, hors détermination identitaire, mas dans I'horizon toujours reconstitué de ses relations d'altérité."

17 Essa autora também faz parte do grupo de pesquisadores vinculados à Université Paris 8 e à AIME, realizando suas pesquisas nestes mesmos contextos médico-sociais destinados aos cuidados de pessoas portadoras de HIV.

18 "(...) articulations discursives inédites, soutenus par de puissantes processualités affectives, recomposent de savoirs sur soi et élaborent de nouvelles organisations du sentir aux potentiels désassujettisssants. (Tradução minha).
} 
destas dinâmicas subjetivas como "afetos somáticos" (GINOT, 2014e, p. 119) e salienta os processos perceptivos e afetivos que atravessam os participantes, como produções inter-relacionais, reiterando uma premissa ético-estética das práticas somáticas como práticas da relação.

Prática fundada em um exercício do comum. Híbrido que mobiliza o corpo a partir da reconexão com o sentir. Cuidado do gesto, da percepção, da enunciação de si que se resvala também em um cuidar de si, dar atenção a si, acompanhar-se. Experiência de trocas que desanestesiam o corpo e os sentidos, deixando-os suscetíveis aos acontecimentos. Ana Maria Rodriguez Costas nos traz uma outra perspectiva disto:

Anestesia e apatia não são sinônimos de entrega, de receptividade, de aceitação, de submissão à experiência. Seja nas proposições de Clark ou nas práticas somático-dançantes, quando alguém se expõe a ser estimulado por um objeto, ou ao contato em movimento com um parceiro, à percepção das sensações, o que está em foco é a estesia relativa aos sentidos (sentir) e a patia, da origem grega pathos, que quer dizer paixão, que se refere a tudo o que pode ser vivenciado como algo novo, ao padecer frente a um acontecimento, algo relativo à mobilidade e à imperfeição. (COSTAS, 2011b, p. 05).

Elisa, Ana e Flávio falam a seguir de outras possibilidades de saúde. Pistas de alguns lugares visitados nos encontros com outras contingências do sentir. Talvez indícios de expressividades que se esboçam. Qualidades perceptivas que abrem espaços de articulação nos ossos e no desejo, desterritorializando algumas camadas da corporeidade instituída do "louco" na conexão com outras territorialidades possíveis. Novos lugares de fala nos quais cada palavra também move microuniversos internos e externos, seja no plano das crenças institucionais do que pode e não pode o corpo dos/as/es usuários/as/es, seja nas maneiras singulares de empoderamento do saber de si, ancoradas no sentir-se.

"É uma coisa de estímulo de não ter desgaste nas coisas do dia-dia mas a gente fica só pensando e não tem esse estímulo de ir se aceitando e melhorando a expressão de ter saúde". (Elisa, Diário de Vivências, 06/10/2016)

"...tem que manter a saúde, fazendo tudo os exercício, e como eu ia fazendo eu ia percebendo que tudo que eu ponho de qualidade na minha vida eu conseguia expressar de volta para o ambiente. É uma coisa como se fosse uma reação de relaxar e entrar em movimento pra atenção mesmo né, assim, coisa bem da cabeça mesmo(...)

Mas é fora do que eu sinto assim, eu fico assim gostando de mim, me apreciando, tendo aquela autoestima pra na harmonia eu conseguir expressar bem né. Porque a expressão do corpo é importante, aí a gente sabe usar ele melhor". (Ana, transcrição de áudio, Diário de Vivências, 26/03/2017)

"Muito bom para o espírito e para o corpo, pode dizer que estou menino no corpo e nas expressões corporais". (Flávio, Diário de Vivências, 09/06/2016) 
"Onde fica o apoio do meu olho todo dia é no chão porque é costume a gente só se olhar do espelho e não de outro jeito, daí, quando eu tiro do chão, eu cresço a minha mente pra outras coisas e vejo os outros e eu". (Ana, Diário de Vivências, 16/04/2016).

Nas dobras deste trabalho, outras insujeições colocaram-se na possibilidade de habitar uma zona de contágios. Nesta, relações artístico-clínica-pedagógicas estão imbricadas e, tanto a prática quanto a escrita, tocam estados de criação de vida ou da vida. No embate entre dançar com a loucura e dançar a loucura, é a vida que se coloca em cena e cria matérias expressivas. Cria territórios nômades e passagens, expondo, para além dos limites de uma prática, vontades de outros mundos, sem barreiras entre dimensões como normalidade e anormalidade, arte e vida, criação artística e criação de si.

Mundos em que todos os corpos viventes importam, e dançam, e criam, e podem se recriar.

"Trabalha o corpo para a mente renovar as atitudes físicas e mentais". (Sérgio, Diário de Vivências, 10/03/2015)

"Eu tô bem, mais estésico assim, na parte da dança, alongamento e corpo, assim é como um vento, uma prática pro pessoal da gente mudá". (Tony, transcrição de áudio, Diário de Vivências, 01/12/2016)

"Eu acho que tudo o que a gente fez ficou para dentro do meu corpo, eu sinto isso, uma mudança dentro". (Ana, transcrição de áudio, 3/03/2016)

\section{Referências}

COSTAS, A. M. R, Abrigos Poéticos. Revista Sala Preta, v. 1, n.11, São Paulo, 2011.

DIÉGUEZ, L. Um teatro sem teatro: a teatralidade como campo expandido. Revista Sala Preta, V.14, n.01, 2014.

GINOT, I. Penser les somatiques avec Feldenkrais - Politiques et esthétiques d'une pratique corporelle. Paris: Éditions L'Entretemps - lignes des corps, 2014.

GINOT, I. Para uma epistemologia das Técnicas de educação somática. Tradução de Joana Ribeiro da Silva Tavares e Marito Olsson-Forsberg. Revista O Percevejo online. Volume 02- N 02 - julho-dezembro/2010

GODARD, H. Olhar Cego: entrevista para Suely Rolnik. In. Lygia Clark: da obra ao acontecimento. São Paulo: Pinacoteca do Estado, 2006.

GODARD, H. Gesto e Percepção. In: PEREIRA, Roberto; SOTER, Silvia (Org.). Lições de Dança 3. Rio de Janeiro: UniverCidade, 1995. P. 11-35. 
LIMA, E. Por uma arte menor: ressonâncias entre arte, clínica e loucura na contemporaneidade. Interface (Botucatu) [online]. 2006, vol.10, n.20, pp.317-329.

LOUPPE, L. Lygia Clark não para de atravessar nossos corpos in: ROLNIK, Suely. (Org.) Lygia Clark: da obra ao acontecimento. Somos o molde. A vocês cabe o sopro. (catálogo de exposição). São Paulo: Pinacoteca do Estado, 2006.

MILLER, J. Qual é o corpo que dança? Dança e educação somática para adultos e crianças. São Paulo: Summus Editorial, 2012.

ONETO, P. D. A que e como resistimos: Deleuze e as artes. In. Lins, D. (Org.). Nietzche/Deleuze: Arte e Resistência: Simpósio Internacional de Filosofia. Fortaleza, 2007. Rio de Janeiro: Forence Universitária, 2007.

PELBART, P. Vida nua, vida besta, uma vida. Trópico, 2007. Disponível em: http://p.php.uol.com.br/tropico/html/textos/2792,1.shl. Acesso em: 15/12/2017.

PELBART, P. Vida Capital: Ensaios de Biopolítica. São Paulo: Iluminuras, 2003.

QUILICI, C. S. O ator performer e as poéticas da transformação de si. São Paulo: Annablume, 2015.

ROLNIK, S. Pensamento, corpo e devir - Uma perspectiva ético/estético/política no trabalho acadêmico. Palestra proferida no concurso para o cargo de Professor Titular da PUC/SP, realizado em 23/06/93, publicada no Cadernos de Subjetividade, v.1 n.2: 241-251. Núcleo de Estudos e Pesquisas da Subjetividade, Programa de Estudos Pós Graduados de Psicologia Clínica, PUC/SP. São Paulo, set./fev. 1993

ROLNIK, S. Subjetividade em obra, Lygia Clark, artista contemporânea. Conferência proferida no Museu d'Art Contemporani de Barcelona.Publicado com o título, Arte cura? Lygia Clark no limiar do contemporâneo, in: Bartucci, Giovanna (org.). Psicanálise, Arte e Estéticas de Subjetivação, Imago, 2002.

ROLNIK, S. Por um estado de arte sem arte - a atualidade de Lygia Clark In TRANS. arts. cultures. Media, Vol. 1, no. 2, 1966. Passim, inc., New York; pp. 73-82. In Núcleo Histórico: Antropofagia e Histórias de Canibalismos, São Paulo: Fundação Bienal de São Paulo, 1998; pp. 456-467

ROLNIK, S. Arte cura? Híbridos de Lygia Clark. Núcleo de subjetividade, 1996 disponível em:

http://www.pucsp.br/nucleodesubjetividade/Textos/SUELY/Hibrido.pdf (visualização em 20/03/2018) 
ROLNIK, S. Seminário Fronteiras, franjas e intervalos. Instituto de Artes UERJ, 2014.

Disponível em: https://www.youtube.com/watch?v=bghAikhX1OE (última visualização em 17/04/2017)

SALVATIERRA, V. Micropolitique des affects somatiques. À propos d'une pratique de Feldenkrais en Appartements de coordination thérapeutique. In: GINOT, I. Penser les somatiques avec Feldenkrais - Politiques et esthétiques d'une pratique corporelle. Éditions L'Entretemps - lignes des corps. Paris. 2014.

TEIXEIRA, L. Conscientização do movimento: Uma prática corporal. São Paulo: Caioá Editora, 1998.

UNO, K. A Gênese de um corpo desconhecido. Trad. Christine Greiner. São Paulo: N-1 Edições, 2012.

VIANA, A. F. Dança e Autismo, espaços de encontro. Tese de doutorado defendida na Faculdade de Educação da UNICAMP, Campinas - SP, 2015 